\title{
La identificación de las empresas de economía social en España. Problemática jurídica ${ }^{1}$
}

\author{
Gemma Fajardo García ${ }^{2}$
}

Recibido: 2 de marzo de 2018 / Aceptado: 25 de abril de 2018

Resumen. La Ley de Economía Social 5/2011 nace con el objetivo de configurar un marco jurídico que de visibilidad a la economía social y le otorgue mayor seguridad jurídica; y con esta finalidad define la economía social y establece los requisitos que deben cumplir las entidades denominadas de economía social. Esos requisitos hacen referencia a la condición de entidad privada, al desarrollo de una actividad económica con criterios empresariales y al cumplimiento de ciertos fines y principios. Las entidades de la economía social deben perseguir el interés general, de forma directa o en conjunción con los intereses de sus miembros usuarios, y deben actuar conforme con ciertos principios que pueden calificarse como estructurales y funcionales. Por último, dice la Ley que las entidades de la economía social serán aquellas incorporadas al catálogo. El catálogo no es un registro de entidades particulares sino un listado de tipos de entidades según la Ley. Estas entidades serán tenidas en cuenta para la elaboración de la información estadística y podrán ser beneficiarias de las políticas de fomento de la economía social. La calificación de una entidad como de economía social se realiza ope legis en el caso previsto en el art. 5.1 de la ley o tras su incorporación al catálogo una vez comprobado el cumplimiento de los requisitos que exige la ley. Es necesario regular reglamentariamente los criterios que deben tenerse en consideración para determinar si se cumplen los fines y principios de la economía social. En cuanto a la acreditación del cumplimiento de esos requisitos por las entidades incorporadas al catálogo, podría ser exigible por la Administración como condición para ser beneficiaria de las medidas de apoyo a la economía social; pero sobre todo deberían ser las propias entidades de la economía social las que asumieran voluntariamente la evaluación del cumplimiento de esos requisitos y su difusión, principalmente a través de la Memoria del ejercicio económico.

Palabras clave: Economía social; Calificación jurídica; Leyes; Estatutos; Catálogo; Registro; Memoria.

Claves Econlit: A13; B55; L31; M41; P13; K29.

1 Este artículo desarrolla la comunicación presentada con el mismo título el 5 de octubre de 2017 en el IX Coloquio Ibérico Internacional de Cooperativismo y Economía Social de CIRIEC, celebrado en Santiago de Compostela, bajo el lema de "Economía Social y globalización: nuevos desafíos, nuevas oportunidades", y es resultado del proyecto de investigación "Economía Social, Autogestión y Empleo (DER2016-78732-R) financiado por el Ministerio de Economía, Industria y Competitividad del Gobierno de España y por el Fondo Europeo de Desarrollo Regional.

2 Universidad de Valencia, España

Dirección de correo electrónico: fajardo@uv.es 


\title{
[en] The identification of social economy companies in Spain. Legal problems
}

\begin{abstract}
The Law of Social Economy 5/2001 was created with the aim of configuring a legal framework that gives visibility to the social economy and gives it greater legal security. The law defines the social economy and establishes the requirements that the so-called social economy entities must meet. These requirements refer to the condition of private entity, the development of an economic activity with business criteria and the fulfillment of certain purposes and principles. The entities of the social economy must pursue the general interest, directly or in conjunction with the interests of its user members, and must act in accordance with certain principles that can be classified as structural and functional. And finally, the entities of the social economy will be those incorporated into the catalog. The catalog is not a register of particular entities but a list of types or categories of entities). These entities will be taken into account for the preparation of statistical information and may be beneficiaries of the policies to promote the social economy. The qualification of an entity as a social economy is performed ope legis in the case provided in art. 5.1 of the law or after its incorporation into the catalog once the compliance with the requirements required by law has been verified. It is necessary to regulate statutorily the criteria that must be taken into consideration to determine if the aims and principles of the social economy are fulfilled. Regarding the accreditation of compliance with these requirements by the entities included in the catalog, it could be required by the Administration as a condition to be a beneficiary of the measures to support the social economy; but above all it should be the entities of the social economy themselves that voluntarily assume the evaluation of compliance with these requirements and their dissemination, mainly through the Annual Report of the financial year.
\end{abstract}

Keywords: Social economy; Laws; Catalogue; Economic memory.

Sumario. 1. Introducción. 2. Definición de Economía Social. 3. Fines que persiguen las entidades de la economía social. 4. Los principios orientadores de las entidades de la economía social. 5. La delimitación de las entidades de la economía social. 6. El Catálogo de entidades de Economía Social. 7. Criterios y medios de acreditación de los fines y principios de las entidades de la economía social. 8. Conclusiones. 9. Referencias bibliográficas.

Cómo citar: Fajardo García, G. (2018) La identificación de las empresas de economía social en España. Problemática jurídica. REVESCO. Revista de Estudios Cooperativos, Segundo Cuatrimestre, No 128, pp. 99-126. DOI: 10.5209/REVE.60209.

\section{Introducción}

En 2009 el Parlamento europeo pedía a la Comisión y a los Estados miembros que reconocieran la economía social como un enfoque diferente de la empresa, cuyo motor principal no es la rentabilidad financiera sino los beneficios para toda la sociedad, y que la incluyeran en su legislación y políticas ${ }^{3}$. Desde entonces son diversos los Estados y regiones que han regulado la economía social principalmente con miras a su reconocimiento y promoción, y entre ellos España ${ }^{4}$.

3 Resolución sobre la Economía Social aprobado por el Parlamento Europeo el 19 de febrero de 2009 (DOUE 25.03.2010). Ver Consideraciones generales $n^{\circ} 8$ y 9. Más ampliamente sobre esta norma y su alcance en Fajardo (2010) o Monzón y Chaves (2012).

4 La economía social ha sido regulada también, siguiendo un orden cronológico, en las regiones belgas de Valonia (Decreto de 20 de noviembre de 2008); Flandes (Decreto de 17 de febrero de 2012) y Bruselas (Orden de 26 de abril de 2012); en Portugal (Ley 30 de Bases de la Economía Social de 8 de mayo de 2013); Francia (Ley no 856 relativa a la Economía Social y Solidaria de 31 de julio de 2014); Rumanía (Ley no 219 de Economía Social de 23 de julio de 2015); Galicia (Ley no 6 de Economía social de 4 de mayo de 2016) y Grecia (Ley no 4430 de Economía Social y Solidaria de 31 de octubre de 2016). Fuera de Europa también 
El 29 de marzo de 2011 fue aprobada en España la Ley de Economía Social $5 / 2011^{5}$. Esta ley nace con el objetivo de configurar un marco jurídico que de visibilidad a la economía social y le otorgue mayor seguridad jurídica. Con esta finalidad, -según su exposición de motivos-, se define la economía social y se establecen los principios que deben contemplar las entidades que la integran. Estos principios son - como dice a continuación, los que van a determinar qué entidades y empresas conforman la economía social. Sin embargo, la utilización por la Ley de diversos criterios para identificar las entidades de economía social, genera dudas a la hora de interpretar las normas, precisamente lo que se trataba de evitar con la aprobación de la Ley. En este trabajo vamos a analizar las normas que dedica la Ley a la identificación de las entidades de la economía social, con ánimo de arrojar algo de luz sobre el tema y proponer algunas medidas que permitan comprobar en cada caso que concurren los principios que, según la ley, caracterizan a las entidades de la economía social u orientan su funcionamiento.

\section{Definición de Economía Social}

El artículo 2 de la ley define la economía social como "conjunto de las actividades económicas y empresariales, que en el ámbito privado llevan a cabo aquellas entidades que, de conformidad con los principios recogidos en el artículo 4, persiguen bien el interés colectivo de sus integrantes, bien el interés general económico o social, o ambos" $"$.

Esta definición de economía social suscita diversas dudas. En primer lugar, la ley define la economía social como un conjunto de actividades económicas y empresariales, cuando no son las actividades por sí mismas las que identifican a la economía social ${ }^{7}$, sino la finalidad perseguida con las mismas y la forma en que se

podemos destacar su regulación en Honduras (Ley del Sector Social de la Economía, Decreto 193 de 30 de octubre de 1985); Colombia (Ley 454 de Economía Solidaria de 4 de agosto de 1998); Ecuador (Ley Orgánica n 444 de la Economía Popular y Solidaria y del Sector Financiero Popular y Solidario, de 10 de mayo de 2011); Méjico (Ley General de Economía Social y Solidaria de 23 de noviembre de 2011) o Quebec (Ley $\mathrm{n}^{\circ}$ 27 de Economía Social de 10 de octubre de 2013).

5 Ley publicada en el BOE 76 de 30 de marzo de 2011. Esta Ley ha sido objeto de análisis por Paniagua (2011); Paz Canalejo (2012); Fajardo (2012); Etxezarreta y Morandeira (2012); Arrieta (2014) o Altzelai (2016) entre otros.

6 Con anterioridad la doctrina había propuesto diversas definiciones, siendo la más reconocida la que recoge el Informe elaborado por los profesores Chaves y Monzón (2008) para el Comité Económico y Social Europeo titulado "La Economía Social en la Unión Europea". Este Informe formula una definición operativa de la Economía Social que permita cuantificar y hacer visible de forma homogénea y armonizada internacionalmente, los principales agregados de las entidades que la integran. Según esta definición, la economía social es el "Conjunto de empresas privadas organizadas formalmente, con autonomía de decisión y libertad de adhesión, creadas para satisfacer las necesidades de sus socios a través del mercado, produciendo bienes y servicios, asegurando o financiando y en las que la eventual distribución entre los socios de beneficios o excedentes así como la toma de decisiones, no están ligados directamente con el capital o cotizaciones aportados por cada socio, correspondiendo un voto a cada uno de ellos. La Economía Social también agrupa a aquellas entidades privadas organizadas formalmente con autonomía de decisión y libertad de adhesión que producen servicios de no mercado a favor de las familias, cuyos excedentes, si los hubiera, no pueden ser apropiados por los agentes económicos que las crean, controlan o financian".

7 Ya en 1989 la Comisión se manifestó al respecto señalando que no son las actividades económicas las que distinguen a las empresas de la economía social, ya que deben poder desarrollar cualquier actividad. La Comisión reconocía que el concepto de economía social no era un concepto operativo a escala comunitaria, 
desarrollan, por ello resulta más adecuado referirse a la economía social como una forma particular de emprender ${ }^{8}$ o de desarrollar actividades económicas ${ }^{9}$.

En segundo lugar hay que entender que, esas actividades son desarrolladas con criterios empresariales, por entidades privadas con personalidad jurídica, y no por personas físicas o entidades públicas. ${ }^{10}$

En tercer lugar la definición legal da a entender que en su actuación esas entidades, que posteriormente denomina entidades de la economía social (EES), persiguen ciertos fines y respetan ciertos principios como ya avanzó la exposición de motivos de la ley; pero como veremos a continuación, estas particularidades no están claramente reflejadas en la ley, son de difícil comprobación, y generan inseguridad jurídica, lo que se trataba de evitar precisamente con la aprobación de la Ley.

\section{Fines que persiguen las entidades de la economía social}

Los fines que persiguen las entidades de la economía social son, según la Ley (art.2): "bien el interés colectivo de sus integrantes, bien el interés general económico o social, o ambos". Pero realmente, estos fines no difieren de los propios de cualquier otra entidad privada. ${ }^{11}$ Lo que la ley debería haber dicho es que las entidades de la economía social persiguen bien el interés colectivo de sus miembros usuarios, bien el interés general, o ambos; o mejor aún, que las entidades de la economía social persiguen el interés general, de forma directa o en conjunción con los intereses de sus miembros usuarios.

Lo primero que debe destacarse es que el fin perseguido por las entidades de la economía social difiere del fin perseguido por las empresas convencionales. Estas, se constituyen normalmente como sociedades civiles o mercantiles con la finalidad de obtener beneficios para ser distribuidos entre sus socios ${ }^{12}$. Por el contrario, las entidades de la economía social cuando desarrollan una actividad económica no lo

pero reflejaba la existencia de determinadas realidades en el conjunto de los Estados miembros que obedecían a principios de organización y funcionamiento similares. Ver en Comunicación de la Comisión al Consejo sobre "Las empresas de la economía social y la realización del mercado europeo sin fronteras", de 18 de diciembre de 1989 (SEC (89) 2187 final).

8 Como dice la Ley francesa de economía social y solidaria de 2014 en su artículo 1 I.

9 La identificación de la economía social con "formas" de desarrollar actividades económicas caracterizadas por sus fines y principios, permite diferenciar tanto formas de organización de la actividad, como modos de actuación o prácticas propias de la economía social. Las primeras constituyen las diversas formas jurídicas de organización de la actividad empresarial, que la ley denomina entidades de la economía social; las segundas son prácticas propias de la economía social (comercio justo, finanzas solidarias, microcrédito, etc.) pero no son identificadas en las leyes como economía social. Sobre la doble perspectiva de economía social como organizaciones y como prácticas, véase Namorado (2017).

10 Entidades reguladas conforme a la Ley 40/2015, de 1 de octubre, de Régimen Jurídico del Sector Público.

11 La sociedad se constituye en interés común de sus socios (art. 1666 Código civil); las asociaciones se constituyen para conseguir fines comunes, de interés general o particular (art. 5 LO 1/2002 Derecho de Asociación); las fundaciones tienen afectado su patrimonio a la realización de fines de interés general (art. 2 Ley 50/2002 de Fundaciones); las cooperativas se constituyen para realizar actividades empresariales, encaminadas a satisfacer sus necesidades y aspiraciones económicas y sociales (art. 1 Ley 27/1999 de Cooperativas).

12 Esta es la finalidad jurídicamente relevante de las sociedades civiles (artículo 1665 del Código civil) y de las sociedades mercantiles (artículo 116 Código de comercio). 
hacen para obtener beneficios distribuibles ${ }^{13}$, sino para satisfacer a través de esa actividad determinadas necesidades de las personas (asociadas o no), en las mejores condiciones posibles ${ }^{14}$.

La actividad económica cobra en las entidades de la economía social mayor relevancia porque suele ser determinante para satisfacer la necesidad para la que se ha creado (vgr. el suministro de productos ecológicos en una cooperativa de consumidores de productos ecológicos, o la atención socio sanitaria a enfermos de alzheimer en una asociación de familiares de alzheimer) ${ }^{15}$. En una empresa convencional la actividad económica es un mero instrumento para la generación de beneficios, y por tanto tiene una función subordinada a este fin; si el objeto social no da beneficios o no los suficientes, habrá que adoptar medidas como la modificación o sustitución de éste $\mathrm{u}$ otras medidas de mayor transcendencia (despido de trabajadores, reestructuración empresarial, venta del negocio, disolución, etc.). Como recuerda uno de los principios de la economía social que luego veremos, en estas entidades se da la primacía de la persona y del objeto social sobre el capital.

El objeto social o actividad económica de las entidades de la economía social es importante en la medida en que permite satisfacer las necesidades de las personas (beneficiarias de las EES).

Los beneficiarios de esa actividad suelen ser colectivos genéricos de personas: usuarios, consumidores, profesionales, proveedores, trabajadores, desempleados, discapacitados, etc., (no inversores).

En unos casos los beneficiarios son a su vez propietarios de la empresa (cooperativas, mutualidades, sociedades laborales, sociedades agrarias de transformación, etc.), mientras que en otros no se da esa coincidencia o al menos no necesariamente (asociaciones, fundaciones, empresas de inserción, centros especiales de empleo, etc.). Pero no son modelos opuestos ya que en el primer caso, todo aquel que comparta la misma necesidad que trata de satisfacer la entidad debe poder acceder fácilmente a la condición de asociado y beneficiarse de los servicios que presta aquella. Esta característica se corresponde con el principio de adhesión voluntaria y abierta de las entidades de la economía social ${ }^{16}$ y refleja su naturaleza solidaria. Además, es propio de las entidades de la economía social que

13 Por ello, en ocasiones, cuando se hace referencia a las características de las EES se suele indicar que no es el lucro el fin primordial de estas entidades, o que son entidades sin fines de lucro, en el sentido de que no suelen distribuir a sus miembros los beneficios del ejercicio.

14 La actividad económica no se presta en las mismas condiciones si la finalidad de la misma es obtener beneficios (maximizando ingresos y reduciendo gastos), que si es dar el mejor servicio (máxima calidad por el menor precio, o máxima remuneración por el trabajo). Pero no debe olvidarse a la hora de determinar cuáles son las mejores condiciones posibles, que la entidad debe mantenerse en el tiempo para poder seguir cumplimiento esta función social, por tanto, las condiciones en que se preste el servicio no deben debilitar económicamente a la empresa. La empresa debe conducirse con criterios de racionalidad y sostenibilidad económica. Como dice el Comité Económico y Social Europeo (CESE): "Las empresas de la economía social son organizaciones que no tienen como único objetivo el obtener beneficios -es decir, éste no es su objetivo primordial- pero deben esforzarse, no obstante, por ser económicamente eficaces para poder utilizar sus excedentes económicos para fomentar sus objetivos" (Dictamen sobre Economía Social y Mercado Único, de 2 de marzo de 2000 (DOCE C117 de 16.4.2000), apartado 3.8.4).

15 Sobre la transcendencia que la actividad cooperativa tiene en la consecución del fin social y en la determinación de los derechos y obligaciones de los socios véase Fajardo (1997) o Vargas (2006)

16 Más ampliamente sobre el principio de adhesión voluntaria y abierta: Serrano (1982) y Duque (1986), y más recientemente: Borjabad (2013); Vargas (2015) o Martínez-Charterina (2017). 
atienden con prioridad a sus propios miembros usuarios, preocuparse también por los intereses de su comunidad o intereses generales ${ }^{17}$.

Por ello suele afirmarse que las entidades de la economía social persiguen bien el interés colectivo de sus miembros usuarios, bien el interés general, lo que se refleja como uno de los principios de la economía social. "la conjunción de los intereses de los miembros usuarios y/o del interés general ". ${ }^{18}$ Pero como dijimos al principio, también suele afirmarse que las entidades de la economía social persiguen simplemente el interés general, bien de forma directa, bien en conjunción con los intereses de sus miembros usuarios ${ }^{19}$; esta expresión consideramos que es más completa y además favorece el fomento de estas entidades $^{20}$.

\section{Los principios orientadores de las entidades de la economía social}

El precepto que comentamos también señala que las entidades de la economía social llevan a cabo esas actividades económicas de conformidad con ciertos principios que se enumeran en el artículo 4; y éste a su vez indica que las entidades de la economía social actúan en base a ciertos principios orientadores. Estos principios parecen cumplir por tanto una doble función, por una parte son rasgos que caracterizan a las entidades de la economía social; y por otra, son pautas que

17 Sirva como ejemplo las cooperativas, constituidas para satisfacer las necesidades y aspiraciones económicas, sociales y culturales de sus miembros, tiene como uno de sus principios el interés por la comunidad lo que se interpreta como que "Las cooperativas trabajan para conseguir el desarrollo sostenible de sus comunidades", porque como dice el Informe sobre la Declaración de la Alianza Cooperativa Internacional, sobre la Identidad Cooperativa, de 1995, aunque las cooperativas son organizaciones que existen principalmente para el beneficio de sus miembros, frecuentemente también están estrechamente ligadas a sus comunidades y tienen una responsabilidad especial para asegurar que se sostenga el desarrollo de éstas económica, social y culturalmente, y deben trabajar también para su protección medioambiental, (Texto editado por el Consejo Superior de Cooperativas de Euskadi en 1995, p. 65). Más ampliamente sobre el principio cooperativo de Interés por la Comunidad en Pedrosa y García Martín (2011).

18 También en este sentido, la Ley de Quebec 27/2013 señala que las empresas de economía social "tienen por objeto satisfacer las necesidades de sus miembros o de la colectividad"; la Ley rumana n 219/2015 dice que esas actividades de la economía social deben ir dirigidas "a servir el interés público, los intereses de la comunidad y/o intereses particulares no patrimoniales” (art. 2), y la Ley griega $\mathrm{n}^{\circ}$ 4430/ 2016 establece como condición que deben cumplir las entidades de la economía social, desarrollar "actividades de interés común y social (satisfaciendo necesidades generales o comunes de sus miembros, realizando actividades de desarrollo sostenible, servicios sociales o inserción social)" (art. 3.1).

19 En este sentido puede citarse la Ley portuguesa 30/2013 para la que las actividades de la economía social persiguen "el interés general de la sociedad sea directamente o a través de la persecución de los intereses de sus miembros, usuarios y beneficiarios, en cuanto que sean socialmente relevantes" (art. 2); y anteriormente el CESE, en su Dictamen de 2000 (vid nota 12) decía que la definición de economía social debe basarse en las principales características que diferencian a ésta de la empresa privada clásica o del sector público, y por ello se debe conceder especial atención a los objetivos (3.8); y añadía a continuación: "Esto significa que la economía social se definirá como aquella que tenga por objeto trabajar para sus miembros y usuarios y para la sociedad a fin de satisfacer necesidades precisas de interés público" (3.8.1).

20 En este sentido puede citarse a Rafael Calvo Ortega $(2005,33)$ quien ha venido defendiendo la necesidad de identificar la economía social con actividades de interés general. En el mismo sentido se han manifestado otros expertos en derecho tributario como Sofía Arana $(2012,87)$ o Salvador Montesinos (2012, 19). Este último, en relación con la ley española critica que la referencia dicotómica al interés colectivo de los integrantes de la entidad y al interés general económico y social acaba distorsionando de forma innecesaria la comprensión acerca de cuál es ese vínculo genérico que permite entablar la ley entre la economía social y el interés general que justifica su promoción. 
deben orientar la actuación de estas entidades. Esta interpretación se refuerza a la vista de la exposición de motivos de la Ley donde se afirma que el artículo 4 presenta los principios que son orientadores y comunes a todas las entidades de la economía social.

Los principios orientadores de las entidades de economía social que enumera el artículo 4 de la Ley no se corresponden, aunque se asemejan, con los principios internacionalmente reconocidos por las organizaciones representativas de la economía social ${ }^{21}$ y que más tarde fueron adoptados por las instituciones europeas como rasgos de identidad de las empresas de economía social. ${ }^{22}$

\begin{tabular}{|c|c|}
\hline Principios. Ley economía social 5/2011 & $\begin{array}{l}\text { Principios. Social Economy Europe } \\
2002\end{array}$ \\
\hline $\begin{array}{l}\text { a) Primacía de las personas y del fin } \\
\text { social sobre el capital, que se concreta } \\
\text { en gestión autónoma y transparente, } \\
\text { democrática y participativa, que lleva a } \\
\text { priorizar la toma de decisiones más en } \\
\text { función de las personas y sus } \\
\text { aportaciones de trabajo y servicios } \\
\text { prestados a la entidad o en función del } \\
\text { fin social, que en relación a sus } \\
\text { aportaciones al capital social". } \\
\text { b) "Aplicación de los resultados } \\
\text { obtenidos de la actividad económica } \\
\text { principalmente en función del trabajo } \\
\text { aportado y servicio o actividad realizada } \\
\text { por las socias y socios o por sus } \\
\text { miembros y, en su caso, al fin social }\end{array}$ & $\begin{array}{l}\text { a) Primacía de la persona y del objeto } \\
\text { social sobre el capital; } \\
\text { b) Adhesión voluntaria y abierta; } \\
\text { c) Control democrático ejercido por } \\
\text { sus miembros (no afecta a las } \\
\text { fundaciones, puesto que no tienen } \\
\text { socios); } \\
\text { d) Conjunción de los intereses de los } \\
\text { miembros usuarios y/o del interés } \\
\text { general; } \\
\text { e) Defensa y aplicación de los } \\
\text { principios de solidaridad y } \\
\text { responsabilidad; a gestión e } \\
\text { f) Autonomía de goder } \\
\text { independencia respecto de los poderes } \\
\text { públicos; }\end{array}$ \\
\hline
\end{tabular}

21 En 2002 la Conferencia Europea Permanente de Cooperativas, Mutualidades, Asociaciones y Fundaciones (CEP-CMAF), institución europea representante de estas cuatro familias de entidades de la economía social, aprobó la Carta de los Principios de la Economía Social. En 2008 esta institución amplió su ámbito de representación a todas las entidades de la economía social y pasó a denominarse Social Economy Europe, pero mantiene dichos principios como señas de identidad frente a las sociedades de capital (http://www.socialeconomy.eu.org/who-see). Como antecedentes de esta Carta suele citarse la Carta de la Economía Social francesa de 1982, y el Informe sobre la Economía Social de Valonia de 1991. La primera definía estas empresas además de por su finalidad de servicio al ser humano, por su forma de organizarse y funcionar, y señalaba como características comunes: la gestión independiente y democrática, la igualdad de derechos y deberes de los socios, la constante formación e información a los socios, la distribución de los excedentes para el crecimiento de la empresa y mejora de los servicios prestados a los socios, promoción de la investigación y desarrollo sostenible de la sociedad. El Informe por su parte, hablaba también de principios como:1) finalidad de servicio a los miembros o a la colectividad, en vez de lucrativa; 2) autonomía de gestión, 3) procesos de decisión democrática; y 4) primacía de las personas y del trabajo sobre el capital a la hora de repartir los beneficios. En estos momentos el concepto de economía social era más estricto al no incluir todavía a las fundaciones

22 Según el Parlamento Europeo, en su Resolución de 2009 (vid nota 1): "Las empresas de la economía social se definen por las características y los valores que comparten: - la primacía de la persona y el objeto social sobre el capital; - la defensa y aplicación de los principios de solidaridad y responsabilidad; - la conjunción de los intereses de los miembros y del interés general; - el control democrático por parte de los miembros; la adhesión voluntaria y abierta; - la autonomía de gestión y la independencia de los poderes públicos; - la movilización de lo esencial de los excedentes para la consecución de objetivos de desarrollo sostenible, la mejora de los servicios a los miembros y el interés general". 


\begin{tabular}{|c|c|}
\hline $\begin{array}{l}\text { objeto de la entidad". } \\
\text { c) "Promoción de la solidaridad interna } \\
\text { y con la sociedad que favorezca el } \\
\text { compromiso con el desarrollo local, la } \\
\text { igualdad de oportunidades entre } \\
\text { hombres y mujeres, la cohesión social, } \\
\text { la inserción de personas en riesgo de } \\
\text { exclusión social, la generación de } \\
\text { empleo estable y de calidad, la } \\
\text { conciliación de la vida personal, } \\
\text { familiar y laboral y la sostenibilidad". } \\
\text { d) "Independencia respecto a los } \\
\text { poderes públicos". }\end{array}$ & $\begin{array}{l}\text { g) Utilización de la mayoría de los } \\
\text { excedentes para la consecución de } \\
\text { objetivos a favor del desarrollo } \\
\text { sostenible, los servicios de interés para } \\
\text { los miembros y el interés general. }\end{array}$ \\
\hline
\end{tabular}

Como puede observarse sólo hay coincidencia en uno de esos principios, el de "independencia respecto de los poderes públicos". El principio de "la adhesión voluntaria y abierta" está totalmente ausente ${ }^{23}$, y la "conjunción de los intereses de las personas usuarias y del interés general" al que hicimos referencia anteriormente, no se recoge en la ley como un principio pero sí está presente en la definición de la economía social. Otros principios se recogen parcialmente o con distinta significación. Este es el caso del principio de "primacía de la persona y del objeto social sobre el capital", que alude al fin social en lugar de al objeto social, con lo que cambia el sentido del principio. La autonomía de gestión y la gestión democrática (en lugar de "control democrático ejercido por sus miembros") se recogen sin mucho sentido como concreción del principio de primacía de las personas y del fin social. En cuanto a la aplicación de los resultados de la actividad económica, además del destino (que no incluye el desarrollo sostenible), la ley española alude a su distribución proporcional a la actividad desarrollada por sus miembros. El principio "defensa y aplicación de los principios de solidaridad y responsabilidad" tampoco se recoge como tal, pero se alude a la solidaridad interna y con la sociedad, como causa para incorporar entre los principios algunos de los objetivos de la responsabilidad social empresarial (RSE) previstos en el artículo 39 de la Ley de Economía Sostenible ${ }^{24}$ : "gestión transparente", "compromiso con el desarrollo local"; "la igualdad de oportunidades entre hombres y mujeres"; "la cohesión social"; "la inserción de personas en riesgo de exclusión social"; "la generación de empleo estable y de calidad"; "la conciliación de la vida personal, familiar y laboral" y "la sostenibilidad"25.

La decisión del legislador de no adoptar íntegramente los principios que identifican internacionalmente a las entidades de la economía social, e incorporar otros que no son exclusivos de las entidades de la economía social genera

23 Especial importancia cobra la ausencia del principio de adhesión voluntaria y abierta, pues como se ha subrayado desde las instituciones europeas, la pertenencia de una entidad de la economía social ha de estar abierta a todo aquél que cumpla los requisitos y acepte las condiciones de ser miembro. (CESE. Dictamen de 2000, apartado 3.8.2, vid nota 12 ).

24 Ley 2/2011, de Economía Sostenible, de 4 de marzo (BOE 55, de 5 de marzo).

25 No se incluyen en cambio otros objetivos como: el buen gobierno corporativo, el compromiso con el medioambiente, el respeto a los derechos humanos, la promoción de la integración de la mujer, o el consumo sostenible, contemplados en el mismo artículo de la ley de economía sostenible. 
confusión, y dificulta la interpretación y aplicación de los principios que deben caracterizar, o al menos orientar, la actividad de esas entidades ${ }^{26}$.

Por ello debería interpretarse este artículo 4 de conformidad con los principios adoptados por la organización empresarial europea de la economía social (Social Economy Europe) y revalidados por las instituciones europeas. La exposición de motivos de la Ley se basa precisamente en estos principios para justificar la creación de un marco jurídico de apoyo y reconocimiento de la economía social como actividad diferenciada.

En cuanto a los objetivos de la responsabilidad social empresarial recogidos como principios, no hay duda de la voluntad del legislador de exigir a estas empresas su cumplimiento, así se refleja y se justifica tanto en la exposición de $\operatorname{motivos}^{27}$, como en el Informe de la Subcomisión para el fomento de la economía social constituida en el seno de la Comisión de Economía y Hacienda del Congreso de los Diputados ${ }^{28}$. La doctrina también se ha hecho eco de la necesidad de que las cooperativas y demás empresas de la economía social cumplan con los objetivos de la responsabilidad social empresarial ${ }^{29}$. Sin embargo, mientras no sean exigibles, puede interpretarse que son recomendaciones como dice el Informe de la subcomisión o principios orientadores de estas entidades, pero no característicos de las mismas, por lo que su cumplimiento no debe serle exigible para su identificación como entidad de la economía social. Cosa distinta es que se pueda exigir a los beneficiarios de medidas de apoyo la correspondiente memoria o informe de sostenibilidad donde se refleje si se cumplen estos objetivos, como veremos más adelante. Esta conclusión se fundamenta en primer lugar en el propio sentido del término "principios orientadores" que puede interpretarse más como una orientación en la actuación, que una exigencia en el cumplimiento de ciertos caracteres $^{30}$; en la compatibilidad de esta conclusión con el marco normativo de la RSE que en ningún caso se impone a las empresas aunque se avance en la exigencia de información sobre la aplicación de ese tipo de medidas ${ }^{31}$, y porque la

26 También en este sentido Altzelai (2016).

27 La exposición de motivos justifica esa nueva exigencia alegando que "la necesidad de aprobar una Ley de la Economía Social conecta directamente con los principios que inspiran y los objetivos que persigue la Ley de Economía Sostenible, en la medida que la economía social es, en cierto modo, precursora y está comprometida con el modelo económico de desarrollo sostenible, en su triple dimensión económica, social y medioambiental".

28 Informe de la Subcomisión para el fomento de la economía social de 26 de mayo de 2011 (BOCG. Congreso de los Diputados $n^{\circ} 581$, de 2 de junio). Este Informe establece como Recomendación ( $\left.{ }^{\circ} 8\right)$ para promover la economía social "Elaborar y difundir memorias de sostenibilidad”, lo cual-considera- "en vez de ser un problema para las empresas de la Economía Social se constata que la cuestión de la transparencia puede ser un elemento constitutivo", y más tarde recomienda que se integren las acciones responsables de las entidades de la economía social en una política global de RSE, para que sirvan de ejemplo al conjunto de los sectores económicos en los que operen para el fomento y la extensión tanto de la economía social como de la RSE (Recomendación $\mathrm{n}^{\circ} 27$ ).

29 Entre otros Mozas y Puentes (2010); Arana (2010); Domínguez (2011); Gadea (2012); Morgado (2012); Socias y Horrach (2013) o Martínez Charterina (2014).

30 Esta conclusión se refuerza con el tenor utilizado por la Subcomisión cuando hace referencia a estos objetivos: "la transparencia puede ser un elemento constitutivo", hay que "Estimular la responsabilidad Social Empresarial", "Deben promoverse y apoyarse aquellas iniciativas orientadas a la incorporación de los criterios de gestión responsable...", "fortalecer y promover prácticas y criterio de buen gobierno y transparencia en estas organizaciones", etc.

31 La Ley 2/2001 sobre Economía Sostenible tienen por objeto "incentivar" a las empresas a incorporar o desarrollar políticas de responsabilidad social (art. 39) y el Informe de la Subcomisión Parlamentaria para 
Estrategia Española de Responsabilidad Social de las Empresas (2014-2020) $)^{32}$ prevé adoptar medidas para extender la práctica de la RSE a todas las empresas con carácter voluntario, aunque están pendiente de desarrollar las medidas necesarias ${ }^{33}$. Hasta el momento, se han adoptado medidas en materia de RSE aplicables a entidades y empresas públicas ${ }^{34}$, y a empresas $\operatorname{cotizadas}^{35}$, pero también se ha creado en el Portal de la Responsabilidad Social del Ministerio de Empleo y Seguridad Social $^{36}$, un sistema que permite que cualquier entidad pueda hacer pública su memoria de responsabilidad o informe de sostenibilidad ${ }^{37}$. La reciente Estrategia Española de la Economía Social 2017-2020 ${ }^{38}$ reitera el compromiso de extender la Estrategia de la Responsabilidad Social a todas las empresas, incluidas las de la economía social a las que define como empresas socialmente

promover la RSE define ésta como "la integración voluntaria por parte de la empresa, en su gobierno y gestión, en su estrategia, políticas y procedimientos, de las preocupaciones sociales, laborales, ambientales y de respeto a los derechos humanos...". En el contexto de la Unión Europea, la Directiva 2014/95/UE que modifica la Directiva 2013/34/UE en lo que respecta a la divulgación de información no financiera e información sobre diversidad, impone a las grandes empresas que cotizan en bolsa y superen los 500 trabajadores, que incluyan en el informe de gestión un estado no financiero que contenga información sobre el impacto de su actividad en relación con cuestiones medioambientales y sociales, así como relativas al personal, al respeto de los derechos humanos y a la lucha contra la corrupción y el soborno. Si la empresa no aplica ninguna política al respecto deberá explicar y motivas en el estado no financiero las razones. Los Estados miembros podrán exigir que la información contenida en el estado no financiero sea verificada por un prestador independiente de servicios de verificación (art. 19 bis).

32 http://www.empleo.gob.es/es/sec_trabajo/EERSE_WEB.pdf

33 Son medidas previstas entre otras: elaborar un reglamento y desarrollar herramientas telemáticas que permitan dar publicidad de la memorias e informes de responsabilidad social y sostenibilidad; puesta en marcha de programas de orientación para las Pymes y entidades de economía social; puesta en marcha de mecanismos de reconocimiento para poner en valor el esfuerzo de las empresas; fomentar la inclusión en los Informes anuales que realicen las distintas entidades de las políticas de creación y mantenimiento de empleo, de igualdad de género, impacto medioambiental de su actividad, etc.

34 La Orden ESS/1554/2016, de 29 de septiembre, regula el procedimiento para el registro y publicación de las memorias de responsabilidad social y de sostenibilidad de las empresas, organizaciones y administraciones públicas (BOE 238, de 1 de octubre).

35 La Directiva 2014/95/UE del Parlamento y del Consejo, de 22 de octubre de 2014, regula la divulgación de la información no financiera e información sobre diversidad de las grandes empresas. Esta normativa se ha integrado en España a través del Real Decreto-ley 18/2017, de 24 de noviembre que ha modificado el Código de comercio, la Ley de Sociedades de Capital y la Ley de Auditoría de Cuentas, en materia de información no financiera y diversidad. Por otra parte, la Comisión Europea (2017/C215/01) aprobó en mayo de 2017 las Directrices sobre la presentación de informes no financieros (https://eur-lex.europa.eu/legalcontent/ES/TXT/PDF/?uri=CELEX:52017XC0705(01)\&from=ES. En España, la "Guía para la elaboración del informe de gestión de las entidades cotizas" incorpora indicadores tanto financieros como no financieros; y la Asociación Española de Contabilidad y Administración de Empresas (AECA) propone un modelo de información integrada de las empresas.

36 http://www.empleo.gob.es/es/rse/index.htm

37 El sistema permite acceder a todas las memorias depositadas y al informe de auditoría de las mismas si se tiene y se ha depositado también. A la hora de publicar la memoria se ofrecen varios tipos y estándares, pero se admiten otros modelos indicándolo. En cuanto al contenido de la Memoria se da la opción de incorporar información sobre al menos uno de los siguientes aspectos: Transparencia en la gestión; Lucha contra la corrupción y el soborno; Mejora de las relaciones laborales; Políticas de diversidad e igualdad; Información sobre aspectos ambientales, sociales y de buen gobierno (ASG); Respeto, protección y defensa de los derechos humanos en toda la cadena de suministro de la entidad proponente; Buen gobierno corporativo; Compromiso con lo social y el medio ambiente; Políticas de accesibilidad universal e inclusión de colectivos en riesgo de exclusión social; Consumo responsable y sostenible; Opiniones de los grupos de interés; Cualesquiera otras que muestren un compromiso con los valores y principios de la RSE y la sostenibilidad.

38 Aprobada por Consejo de Ministros de 29 de diciembre de 2017 y publicada por Resolución de 15 de marzo de 2018 de la Secretaría de Estado de Empleo (BOE 69, de 20 de marzo de 2018). 
responsables. El eje 10 de la estrategia establece diversas medidas para impulsar la responsabilidad social en el marco de estas entidades ${ }^{39}$.

En resumen, podemos concluir señalando que hay principios que caracterizan a las entidades de la economía social, que han sido reconocidos internacionalmente, y que también están presentes en el artículo 4, sin excluir el principio de adhesión voluntaria y abierta; y hay otros principios que son orientadores de la actividad de las entidades de la economía social como son los objetivos de la RSE. Estos, si bien no deberían ser exigibles para acceder al catálogo de entidades de la economía social, si podrían serlo a la hora de beneficiarse de políticas de promoción de la economía social, si es que quiere promoverse su cumplimiento.

\section{La delimitación de las entidades de la economía social}

Las entidades de la economía social podrían definirse por tanto como personas jurídicas de derecho privado, que desarrollan una actividad económica con criterio empresarial y de conformidad con ciertos principios, con el fin de perseguir el interés general, de forma directa o en conjunción con los intereses de sus miembros usuarios.

Pero el legislador ha ido más allá a la hora de delimitar las entidades de la economía social. El artículo 5 de la Ley, bajo el título de "Entidades de la economía social" comienza señalando que: "Forman parte de la economía social las cooperativas, las mutualidades, las fundaciones y las asociaciones que lleven a cabo actividad económica, las sociedades laborales, las empresas de inserción, los centros especiales de empleo, las cofradías de pescadores, las sociedades agrarias de transformación y las entidades singulares creadas por normas específicas que se rijan por los principios establecidos en el artículo anterior".

Por su parte, el apartado $2^{\circ}$ de este mismo artículo 5 añade: "Asimismo, podrán formar parte de la economía social aquellas entidades que realicen actividad económica y empresarial, cuyas reglas de funcionamiento respondan a los principios enumerados en el artículo anterior, y que sean incluidas en el catálogo de entidades establecido en el artículo 6 de esta Ley".

Este precepto amplía el ámbito de las potenciales entidades de la economía social a cualquier persona jurídica de derecho privado que realice una actividad económica con criterio empresarial, aunque no reúna la forma o calificación jurídica de las entidades enumeradas en el apartado anterior, si sus reglas de funcionamiento responden a los principios orientadores del artículo 4 , y además se incluye en el catálogo de entidades establecido en el artículo 6 de la ley.

39 Las medidas que se citan son: 54 Promover la aplicación de la Estrategia Española de Responsabilidad Social de las Empresas 2014-2020 a la economía social; 55º Impulsar la realización de memorias de RSE por la parte de las entidades de la economía social y difusión a través del Portal de Responsabilidad Social del Ministerio de Empleo y Seguridad Social; $56^{\circ}$ Generar espacios de buenas prácticas e intercambio de experiencias en el ámbito de la responsabilidad social para las entidades de la economía social; $57^{\circ}$ Promover la incorporación de la responsabilidad social aplicada al territorio en las actuaciones de la economía social, y $58^{\circ}$ Apoyar y coordinar con las herramientas de medición de la responsabilidad social existentes en otros ámbitos ministeriales con competencias en economía social, como con el Ministerio de Agricultura y Pesca, Alimentación y Medioambiente, que puso en marcha el Observatorio de la Sostenibilidad en España (http://www.observatoriosostenibilidad.com/). 
Esta norma abre nuevos interrogantes en la identificación de las entidades de la economía social.

En primer lugar, de la lectura de ambos párrafos parece desprenderse que sólo a las entidades calificadas como entidades de la economía social conforme al segundo párrafo les es exigible que sus reglas de funcionamiento respondan a los principios orientadores de la economía social; mientras que las primeras (cooperativas, mutualidades, fundaciones y asociaciones que lleven a cabo actividad económica, sociedades laborales, empresas de inserción, etc.) no necesitan demostrar que sus reglas de funcionamiento responden a esos principios para ser consideradas entidades de economía social.

En efecto, la identificación como entidades de economía social de estas organizaciones, atendiendo a su forma o calificación jurídica, plantea la duda de si es suficiente con cumplir este requisito o también serán exigibles los demás (actividad, fines y principios). Solo en el último caso se aclara que las entidades singulares creadas por normas específicas deberán regirse por los principios establecidos en el artículo 4 para ser consideradas entidades de economía social ${ }^{40}$.

La respuesta está en el marco jurídico de estas entidades, todas ellas son entidades $^{41}$ de derecho privado ${ }^{42}$, que pueden desarrollar actividades económicoempresariales $^{43}$, y las que lo hagan cumplirán por tanto el primer requisito; todas

40 La aclaración no sería necesaria en el caso de la entidad singular Organización Nacional de Ciegos Españoles (ONCE), pues se aprovechó la propia Ley de Economía Social para su reconocimiento jurídico como "entidad singular de economía social" (Disposición adicional tercera).

41 El concepto de entidad no se corresponde necesariamente con la personalidad jurídica. Como ya destacó el Comité Económico y Social Europeo en la definición de la economía social ha de ponerse el acento en su organización formal y no en su personalidad jurídica, que puede tener o no (vid nota 12). Así por ejemplo, los centros especiales de empleo -según la Ley General de derechos de las personas con discapacidad y de su inclusión social (RD. Legislativo 1/2013, de 29 de noviembre)- se definen por su objeto social (realizan una actividad productiva de bienes o de servicios para el mercado) y por su fin (aseguran un empleo remunerado para las personas con discapacidad, y favorecen su inclusión en el empleo ordinario), pero no se exige que tengan personalidad jurídica.

42 No son entidades públicas. La Ley 4/2007, de 3 de abril de transparencia de las relaciones financieras (BOE 81 de 4 de abril) identifica como empresa pública cualquier empresa en la que los poderes públicos puedan ejercer, directa o indirectamente, una influencia dominante en razón de la propiedad, de la participación financiera o de las normas que la rigen (art. 2). Algunas EES pueden cuestionarse a la vista de esta norma, como las cooperativas de servicios públicos (que deben estar promovidas y controladas por la administración: art. 99 de Ley valenciana de cooperativas de 15 de mayo de 2015) o corporaciones públicas como las cofradías de pescadores. Pero estas últimas no quedan excluidas de las EES ya que entre sus funciones está la de prestar servicios a sus miembros (art. 46 de la Ley 3/2001, de 26 de marzo de Pesca Marítima del Estado). Estos servicios pueden prestarse mediante el ejercicio de actividades económico-empresariales, atendiendo a fines de interés general y respetando los principios de la economía social, incluyendo la gestión autónoma e independiente respecto de los poderes públicos. Las cofradías pueden desarrollar estas actividades directamente o a través de la constitución de una organización de productores como prevé el Reglamento (UE) 1379/2013, del Parlamento Europeo y del Consejo, de 11 de diciembre de 2013. Más ampliamente sobre la actividad privada y mutualista de las cofradías de pescadores en Cervera (2010).

43 La mayor parte de las entidades citadas en el art. 5 son formas jurídicas de organización de actividades empresariales (cooperativas, mutualidades, sociedades laborales, empresas de inserción, centros especiales de empleo o sociedades agrarias de transformación). Otras entidades sólo podrán considerarse pertenecientes a la economía social cuando puedan acreditar que llevan a cabo actividades económicas y empresariales. Este es el caso de las asociaciones y fundaciones. Las primeras realizarán las actividades necesarias para el cumplimiento de sus fines (art. 13 Ley de Asociaciones 1/2002, de 2 de marzo) y las fundaciones podrán desarrollar actividades económicas cuyo objeto esté relacionado con los fines fundacionales o sean complementarias o accesorias de las mismas; así mismo, podrán intervenir en cualquier actividad económica a través de su participación en sociedades (art. 24 Ley de Fundaciones 50/2002, de 26 de diciembre). Sobre la calificación de las fundaciones como entidades de economía social, véase Feliu (2011). 
ellas por definición tienden a satisfacer intereses generales (directamente o en conjunción con los intereses de sus miembros usuarios $)^{44}$ y todas ellas cumplen los principios de la economía social o los persiguen en su actuación, como se puso de manifiesto en el Informe para la Ley de Fomento de la Economía Social ${ }^{45}$. Dentro de los principios, algunos son estructurales porque vienen exigidos por la forma o calificación jurídica adoptada; mientras que otros son funcionales o conductuales, porque dependen de cómo se comportan las personas y entidades, y en estos casos la forma o calificación jurídica de la entidad no garantiza su cumplimiento. ${ }^{46}$ Puede concluirse por tanto que las entidades incluidas en el párrafo primero del artículo 5 son entidades de la economía social porque cumplen los principios estructurales de la economía social precisamente por razón de su forma o calificación jurídica (son entidades que persiguen fines mutualistas o de interés general) y cabe presumir que también cumplirán los principios funcionales o propiamente orientativos.

En segundo lugar, nos preguntamos si estas entidades a las que hace referencia el $2^{\circ}$ párrafo, tienen que cumplir también el requisito finalista, es decir perseguir con su actividad el interés general, de forma directa o en conjunción con los intereses de sus miembros usuarios. Pensamos que la respuesta debe ser afirmativa y por tanto debe entenderse que estas entidades deben cumplir todos los requisitos: desde su condición de entidad de derecho privado, su actividad económico empresarial, sus fines y principios; como exige el artículo segundo al definir la

44 Las entidades de la economía social descritas en el artículo 5.1 tienen como objetivo satisfacer necesidades de carácter socio-económico, de sus miembros o de su entorno, y así se contempla en la propia ley. Este es el caso de las cooperativas, creadas para satisfacer las necesidades de sus miembros (art. 1.1. Ley de Cooperativas 27/1999); las mutuas de seguros y mutualidades de previsión social, que prestan cobertura a sus socios(arts. 41 y 43 Ley 20/2015, de 14 de julio); las sociedades laborales que generan empleo estable para sus socios (Ley 44/2015, de 14 de octubre); las sociedades agrarias de transformación, que prestan servicios agrarios a sus asociados (arts. 1.1 y 5.1 Real Decreto 1776/1981, de 3 de agosto); las cofradías de pescadores, que prestan servicios a sus miembros (art. 46 Ley 3/2001 de 26 de marzo); las asociaciones que promueven el interés general y las que no restrinjan su actividad a beneficiar a sus asociados (art. 32 Ley 1/2002, de 2 de marzo); las fundaciones que realizan fines de interés general (art. 2.1. Ley 50/2002, de 26 de diciembre); las empresas de inserción que tienen como fin social la integración socio-laboral de personas en situación de exclusión (art. 1 Ley 44/2007, de 13 de diciembre); los centros especiales de empleo que crean empleo remunerado para personas con discapacidad (art. 43 RD Legislativo 1/20013, de 29 de noviembre).

45 Este Informe fue elaborado por una Comisión independiente de personas expertas, designadas por el Gobierno de cara a la aprobación de la Ley de Economía Social. El Informe fue publicado por el Ministerio de Trabajo de Inmigración bajo el título de Informe para la elaboración de una ley de fomento de la economía social (Monzón, J.L., Calvo Ortega, R.; Chaves, R; Fajardo, G y Valdes Dal Re, F., 2010).

46 Los principios de la economía social internacionalmente reconocidos son por lo general principios estructurales, están integrados en la estructura de la entidad por imperativo legal: la primacía de la persona y del objeto social sobre el capital; la adhesión voluntaria y abierta; el control democrático por sus miembros; la conjunción de los intereses generales con los intereses de los miembros usuarios; la autonomía de gestión e independencia de los poderes públicos, o la forma de distribuir los resultados, se corresponden con normas que regulan estas formas jurídicas. Estos principios se corresponden en buena medida con los llamados principios cooperativos, que a su vez se inspiran en normas propias de las asociaciones y mutualidades. Estos principios están presentes estructuralmente en las entidades clásicas de la economía social y muchos de ellos también en aquellas otras entidades con las que comparten fines, formas organizativas y pautas de comportamiento. No debe ignorarse la proximidad existente entre las sociedades laborales y las cooperativas de trabajo asociado; las sociedades agrarias de transformación y las cooperativas agrarias, o las cofradías de pescadores y las cooperativas de pesca. Todas ellas comparten la misma condición de sus miembros y suelen estar abiertas a nuevos miembros de la misma condición (trabajadores, agricultores, pescadores); comparten los objetivos (atender las necesidades de sus miembros) y en muchos casos, la forma de organizarse (gestión democrática y distribución de los resultados en atención al trabajo o actividad prestada en la entidad, más que en proporción al capital aportado). Por el contrario, principios como los que incorporan los objetivos de la RSE son principalmente conductuales. 
economía social; de lo contrario perdería su sentido esta norma que es clave para la comprensión de la economía social en España.

En tercer lugar, nos cuestionamos cual es la función del catálogo de entidades: ¿es un requisito más para ser considerada una entidad como de economía social?, o ¿es precisamente con la inscripción en el catálogo como se adquiere la consideración de entidad de la economía social?, ¿deben incluirse en el catálogo todas las entidades de la economía social?, ¿cómo debe demostrarse que se cumplen los requisitos de actividad, fines y principios?

\section{El Catálogo de entidades de Economía Social}

Antes de analizar la regulación del Catálogo en la ley, conviene recordar algunos antecedentes de esta norma ${ }^{47}$. La propuesta de ley marco de economía social elaborada por CEPES dedicaba el art. 5 al "Registro", y establecía que en el Ministerio de Trabajo e Inmigración se creará un Registro administrativo de las entidades de economía social y de sus organizaciones representativas, a efectos estadísticos y para el conocimiento de su presencia y representación económica y social $^{48}$. Esta propuesta no aclaraba si la inscripción en este Registro debía hacerse a instancias de cada entidad o si debía ser la Administración quien procediera a la misma. El texto articulado propuesto por el grupo de expertos contemplaba en cambio, la creación de un catálogo de las diferentes clases de organizaciones y entidades integrantes de la economía social, en lugar de un registro de entidades. La diferencia principal entre ambas propuestas parece estar en el sujeto de inscripción, ya que no se trataría de entidades individuales, que deban inscribirse a iniciativa propia o de la Administración Pública, sino de categorías de entidades calificadas por rasgos comunes, y cuya inscripción correría a cargo de la Administración. Este texto es el que tomó el proyecto de ley aunque ligeramente matizado, ya que habla de tipos de entidades y no de clases. Durante la tramitación parlamentaria se intentó sin éxito establecer paralelamente al catálogo, un registro de entidades de economía social cuya inscripción fuera constitutiva y otorgase la consideración de social a las entidades inscritas ${ }^{49}$. También en la doctrina, alguna voz autorizada abogaba por la creación de un registro administrativo con funciones de calificación, que permitiera verificar conforme a derecho la existencia de una entidad de economía social, y criticaba que el sistema de catálogo pudiera asegurar esa función (Sánchez Pachón, 2010, 57).

47 Como recoge la propia exposición de motivos de la Ley, el proyecto de ésta fue resultado de la integración de dos documentos: la propuesta de Ley Marco de la Economía Social presentada por CEPES (Confederación Empresarial Española de la Economía Social), y el Informe para la elaboración de la Ley de Fomento de la Economía Social, de la Comisión de Expertos (vid nota 43).

48 Un análisis de esta propuesta puede seguirse en Alfonso (2010).

49 Propuesta presentada en el Congreso de los Diputados por el Grupo Parlamentario Esquerra Republicana Izquierda Unida - Iniciativa per Catalunya Verds como enmienda $\mathrm{n}^{\mathrm{o}} 16$. Esta propuesta de registro parece ser compatible con la subsistencia del catálogo, a la vista de la justificación que se da a otra enmienda del mismo Grupo ( $\left.\mathrm{n}^{\circ} 8\right)$, donde se dice que es necesario mantener un catálogo de las diferentes tipologías de instituciones que puedan confluir en el concepto de economía social. 
Sin embargo, el texto finalmente aprobado mantiene la opción del catálogo, el cual recogerá "los diferentes tipos de entidades integrantes de la economía social" (artículo 6). El catálogo previsto en la Ley 5/2011 no es por tanto un Registro administrativo donde tengan que inscribirse las entidades individuales, pero tampoco queda claro si el mismo se compondrá de tipos (o categorías) de entidades, o de entidades individuales. Para aportar algo de luz ante esta incógnita podríamos tomar en consideración otras figuras análogas de reciente creación por la Administración así como la función que el catálogo está llamado a cumplir.

En efecto, el sistema de identificación utilizado en la Ley de Economía Social parece haberse replicado en la Ley 43/2015, del Tercer Sector de Acción Social (Disposición adicional segunda), cuando trata de delimitar las entidades que integran este sector. La Ley no habla en esta ocasión de Catálogo sino de Inventario, pero igualmente remite al Ministerio (en este caso de Sanidad, Servicios Sociales e Igualdad) la competencia para, en colaboración con las comunidades autónomas, elaborar y mantener actualizado el "Inventario de entidades del Tercer Sector de Acción Social". Dicho inventario "se organizará en función de los diferentes tipos de entidades" y en coordinación con los registros y catálogos existentes en las comunidades autónomas ${ }^{50}$. Durante la tramitación de esta Ley se propuso sustituir la denominación de "Inventario" por la de "Registro" y no fue aceptada ${ }^{51}$. También merece recordarse que el Consejo Económico y Social en su Dictamen de 25 de febrero de 2015 sobre dicha Ley veía conveniente precisar más el contenido de esta disposición, pues no quedaba clara su función ni la necesidad de realizar un informe previo por parte del Consejo Estatal de Organizaciones no Gubernamentales de Acción Social (pág. 13).

Posteriormente se aprueba la Ley 6/2016 de 12 de mayo del Tercer Sector Social de Euskadi, y regula el "Censo de organizaciones del tercer sector social de Euskadi” (art. 5). Este censo público será creado y actualizado por el departamento competente en materia de servicios sociales del Gobierno Vasco, y en el mismo se inscribirán las organizaciones del tercer sector. Para poder colaborar con las administraciones públicas vascas y tener acceso a las medidas de promoción que éstas impulsen, las concretas organizaciones del tercer sector deberán estar inscritas en el citado Censo.

Tanto el Catálogo de entidades de la Economía Social como el Inventario de entidades del Tercer Sector de Acción Social, se conforman como instituciones que centralizarán la información procedente de otros catálogos y registros de entidades existentes en la Administración central o autonómica. En efecto, el catálogo de entidades de la economía social tiene ámbito estatal y se nutrirá con información proveniente de registros de ámbito estatal y de ámbito autonómico, por lo que se hace necesario que las diferentes administraciones autonómicas colaboren e

50 En este caso se consideran entidades del Tercer Sector, "aquellas organizaciones de carácter privado, surgidas de la iniciativa ciudadana o social (...) que responden a criterios de solidaridad y de participación social, con fines de interés general y ausencia de ánimo de lucro, que impulsan el reconocimiento y el ejercicio de los derechos civiles, así como de los derechos económicos, sociales o culturales de las personas y grupos que sufren condiciones de vulnerabilidad o que se encuentran en riesgo de exclusión social" (art. 2.1); y en todo caso, lo serán las asociaciones, las fundaciones, y las federaciones o asociaciones que las integren, siempre que cumplan con lo previsto en dicha Ley (art. 2.2).

51 Véase en la Memoria del análisis de impacto normativo del proyecto de Ley del Tercer Sector de Acción Social, elaborado por el Ministerio de Sanidad, Servicios Sociales e Igualdad, el 20 de marzo de 2015. 
informen a la Administración General del Estado del contenido de sus respectivos registros $^{52}$.

Así mismo, las diversas comunidades autónomas podrán a su vez centralizar la información relativa a las diversas entidades de la economía social registradas o sitas en su territorio.

Este es el caso de Galicia, que aprobó el 4 de mayo de 2016 una Ley de Economía Social ${ }^{53}$, y regula la creación y funcionamiento del Catálogo gallego de entidades de la economía social (art. 7). En este caso es la consejería competente en materia de economía social de la Xunta la que, previo informe del Consejo de la Economía Social de Galicia, elaborará y mantendrá actualizado el catálogo gallego. Para ello, todos los órganos de la administración general de la Comunidad Autónoma con competencias registrales sobre las entidades de la economía social que se citan en el artículo 6 de dicha ley deberán notificar y remitir anualmente a dicha consejería para su inclusión en el Catálogo gallego, una relación de las inscripciones efectuadas en dichos registros relativas a la constitución, fusión, transformación o disolución de tales entidades. Este catálogo, que será único para Galicia, no tendrá carácter constitutivo, y "se elaborará de forma coordinada con el Catálogo de entidades de economía social de ámbito estatal".

El catálogo de entidades de la economía social gallego, así como el inventario de entidades del tercer sector de acción social y el censo de entidades del tercer sector social vasco se conciben como listados de entidades conformados por la autoridad competente a partir de la información existente en otros catálogos o registros, y organizados según tipos de entidades. Este podría ser también el sentido que podría darse al Catálogo estatal de entidades de la economía social. Se trataría así de un listado de todas las entidades de la economía social organizas según tipologías: cooperativas, mutualidades, fundaciones, asociaciones, sociedades laborales, empresas de inserción, centros especiales de empleo, cofradías de pescadores, sociedades agrarias de transformación, entidades singulares y otras tipologías que con el tiempo puedan crearse y/o incorporarse al catálogo, como podrían ser las Comunidades y Mancomunidades de Montes Vecinales en mano común, que incorpora a su catálogo la Ley gallega de economía social $^{54}$.

Tanto el catálogo estatal como el catálogo gallego de entidades de economía social dicen ser públicos y se comprometen a hacer efectiva dicha publicidad por medios electrónicos.

Conocer la función que está llamado a cumplir el catálogo de entidades de economía social también nos puede dar luz sobre la información que podría o

52 La necesaria colaboración entre ambas administraciones se incorporó durante la tramitación como consecuencia de la enmienda $n^{\circ} 34$ presentada por el Grupo Parlamentario Popular. En su justificación dice esta enmienda que "el objetivo final de la colaboración entre la Administración General del Estado y las Administraciones autonómicas debe ser facilitar a los ciudadanos el acceso a la información, unificando el conjunto de catálogos en un solo punto de acceso a la información".

53 Sobre la aprobación y contenido de esta Ley véase Vázquez (2016-2017).

54 La ley gallega 6/2016 al señalar los tipos de entidades de economía social contempla todas las previstas en el artículo 5.1 de la Ley estatal y además: "las comunidades y mancomunidades de montes vecinales en mano común" (art. 6.1 i). Este modelo de organización se encuentra regulado a nivel estatal por la Ley 55/1980 de 11 de noviembre; y en Galicia por la Ley 13/1989 de 10 de octubre, de Montes Veciñais en Man Común (DOG n ${ }^{\circ} 202$ de $2^{\circ}$ de octubre). 
debería incorporar. La Ley no da muchas pistas al respecto por lo que las dudas que suscita son innumerables. Se discutió durante el debate parlamentario con ocasión de la aprobación de la Ley, si el catálogo tenía eficacia constitutiva o no. Si tuviera eficacia constitutiva significaría que la inscripción o mención de la entidad en el catálogo sería suficiente para que fuera considerada entidad de economía social y acreedora de los derechos, deberes y beneficios reconocidos a éstas. Esta interpretación podría desprenderse de la lectura del art. 5.2 cuando dice que forman parte de la economía social aquellas entidades que tras cumplir los requisitos señalados "sean incluidas en el catálogo". Sin embargo, y aunque la Ley ya no dice nada al respecto del carácter constitutivo o no del catálogo, lo cierto es que la Memoria presentada por el Ministerio de Trabajo e Inmigración acompañando el anteproyecto decía que el catálogo "no tiene efectos constitutivos, sino que se trata de un listado ordenado y clasificado de los distintos tipos de entidades de la Economía Social, y por lo tanto no incluye los datos de las empresas o entidades registradas en concreto, circunstancias por las que no se adopta la forma de Registro"55. Mientras que el Informe del Consejo Económico y Social presentado en relación con el mismo proyecto echaba en falta una explícita referencia al carácter exclusivamente informativo y estadístico del catálogo, así como una regulación del mismo que contemplara aspectos como su publicidad, los requisitos y formas de acceso al mismo, o la coordinación necesario que deberá darse con otros instrumentos similares existentes en el ámbito autonómico. La Ley, como decimos, no recogió expresamente el carácter no constitutivo del catálogo pero sí está presente en su exposición de motivos ${ }^{56}$, por lo que deberemos tenerlo en cuenta en la interpretación de la norma.

Por otra parte, el catálogo servirá de referencia a la hora de elaborar la información estadística sobre las entidades de la economía social. Como dice la disposición adicional primera de la ley: "El Ministerio de Trabajo e Inmigración adoptará, en colaboración y coordinación con los departamentos ministeriales y las Administraciones que pudieran tener competencia en materia registral de las entidades de la economía social, y previo informe del Consejo para el Fomento de la Economía Social, las medidas necesarias para garantizar una información estadística de dichas entidades así como de sus organizaciones de representación, periódicamente actualizada y ajustada en su clasificación al catálogo previsto en el artículo 6 de esta Ley". Téngase en cuenta que la información estadística es competencia del Estado (art. 149.1.31 CE) y para ello el Estado debe contar con la colaboraciones de las demás administraciones ${ }^{57}$. Pero esta información estadística será recabada a partir del principio de colaboración entre Administraciones. El catálogo será tenido en cuenta en atención a la calificación de entidades de la economía social existente en ese momento, de forma que la información recopilada se ajuste a esa clasificación.

55 Un análisis del debate parlamentario sobre este y otros puntos de la Ley puede seguirse en Paz Canalejo 2012: 157-159).

56 La exposición de motivos en su apartado III hace referencia al artículo 6 del cual dice que "regula el catálogo de entidades de la economía social, que será elaborado y actualizado por el Ministerio de Trabajo e Inmigración previo informe del Consejo para el Fomento de la Economía Social, no teniendo en ningún caso carácter constitutivo".

57 Sobre la información estadística de las entidades de la economía social y los criterios a seguir en su determinación véase: Barea y Monzón (1995). 
A pesar de la escasa información que ofrece la Ley y de la inexistencia de una norma reglamentaria que permita dar efectividad a la misma, siete años después de su aprobación, parece claro que el Catálogo no cumple una función constitutiva a los efectos de reconocer la condición de entidades de la economía social a personas jurídicas concretas, ni de otorgarle derechos o beneficios, como ocurre con el Censo de entidades del tercer sector social en el País Vasco. Por el contrario, cumple una función delimitadora de los tipos de entidades de la economía social, a efectos de cuantificar su relevancia en las estadísticas estatales. Y, por último, cabe preguntarse si, aunque sólo sea a efectos informativos, el Catálogo debe o debería listar qué entidades particulares son consideradas entidades de la economía social. Esta última función sería de gran interés porque permitiría recopilar a nivel nacional estas entidades que actualmente se encuentran dispersas en diversos registros nacionales e autonómicos (registros de cooperativas, de asociaciones, de fundaciones, registro de sociedades laborales, de empresas de inserción, de centros especiales de empleo, etc.). Esta es la función que ley gallega de economía social ha encomendado al catálogo gallego, y que si el ejemplo se siguiera en otras comunidades autónomas facilitaría que pudiéramos tener una visión más global y real de la economía social en España.

Si el catálogo ofreciera información no sólo sobre los tipos de entidades de la economía social, como dice la Ley estatal, sino también sobre las concretas entidades que se integran en cada tipo, como dice la Ley gallega, el catálogo ganaría relevancia y su información sería de gran interés para administraciones, empresas, universidades y particulares. Sin embargo, la Estrategia Española de Economía Social 2017-2020 reitera conforme con la Ley que el catálogo de las entidades de la economía social contendrá "los diferentes tipos de entidades integrantes de la economía social", y reserva la identificación de las concretas entidades (empresas y organizaciones) al llamado "Sello de Entidad de la Economía Social".

La Estrategia contempla como $19^{\circ}$ medida, la creación de dicho sello de reconocimiento de estas entidades que permitirá "identificar a todas y cada una de las empresas y organizaciones que conforman el sector" y "dotarles de visibilidad de manera que sean reconocidas por la sociedad en su conjunto". Pero la determinación de qué entidades serán merecedoras de este sello no parece depender de su mención en el Catálogo (de tipos de entidades y no de entidades), sino de una Orden Ministerial que establecerá los requisitos necesarios para la obtención del sello.

\section{Criterios y medios de acreditación de los fines y principios de las entidades de la economía social}

En el capítulo anterior hemos analizado la función del catálogo y hemos llegado a la conclusión de que el mismo no tiene una función constitutiva ni le está reservada la calificación de las entidades de la economía social. El catálogo parece que limitará su función a recabar y hacer pública información procedente de otros registros y catálogos de entidades de economía social. Pero esta labor estará sometida a cierto control, el Consejo para el Fomento de la Economía Social, tiene 
encomendada la tares de evacuar informe previo, de conformidad con el artículo 6 de la Ley, en la elaboración y actualización del catálogo de entidades de la economía social del Ministerio de Trabajo (art. 9.2 c).

No obstante lo anterior, concluir que el catálogo no cumple una función constitutiva no resuelve todas las dudas que nos habíamos planteado, porque faltaría saber si todas las entidades pertenecientes a los tipos incluidos en el catálogo, serán consideradas entidades de la economía social, o si deberá comprobarse que cumplen los requisitos de actividad, fines y principios, en cuyo caso, habrá que determinar quién se ocupará de tal tarea y cómo se llevará a cabo ${ }^{58}$.

En Francia, la Ley no 2014-856 de 31 de julio de Economía social y solidaria adopta un doble criterio, por una parte, considera empresas de la economía social a las personas jurídicas de derecho privado constituidas como cooperativas, mutualidades, fundaciones y asociaciones (artículo 1, II. $1^{\circ}$ ), y por otra, a las sociedades mercantiles que cumplan determinadas condiciones previstas en el apartado $2^{\circ}$ del artículo 1, II de la Ley, y que se inscriban en el registro de comercio y de sociedades con la mención de "empresa de la economía social y solidaria" (art. 1, III).

Podría pensarse que la Ley española de economía social ofrece una solución similar al diferenciar por una parte entidades de la economía social por su forma o calificación jurídica (art. 5.1) y por otra, entidades que lo serán porque sus reglas de funcionamiento respondan a los principios de la economía social y estén incluidas en el catálogo (art. 5.2). Pero esta no es una solución satisfactoria; por una parte, porque no todas las entidades cuya forma o calificación jurídica pertenece a alguno de los tipos de entidades de la economía social cumplen siquiera los principios estructurales de la economía social ${ }^{59}$; y por otra, porque los principios orientadores de la economía social no recogen sólo rasgos estructurales sino también conductuales cuyo cumplimiento debería poderse demostrar, porque no está vinculado a la forma o calificación jurídica adoptada.

La Ley debe dar una respuesta clara, porque no olvidemos que su objetivo es según su exposición de motivos- por una parte "el reconocimiento y mejor visibilidad de la economía social, otorgándole una mayor seguridad jurídica por medio de las actuaciones de definición de la economía social, estableciendo los principios que deben contemplar las distintas entidades que la forman"; y por otra "la promoción, estímulo y desarrollo de las entidades de la economía social y de sus organizaciones representativas".

La identificación de las entidades de economía social es importante y tiene consecuencias: su visibilización y fomento, esto último precisamente, en consideración a sus fines y principios (art. 1); por ello debe haber coherencia entre quienes puedan ser beneficiarias de ese fomento y quienes se incorporen en el catálogo (si es el caso) o sean acreditadas con el Sello de entidad de la economía social. Puesto que la identificación de una entidad como de economía social va a

58 Estas mismas dudas se plantea Arrieta (2014) o Altzelai (2016).

59 Podría citarse el caso de centros especiales de empleo que no pertenecen a la economía social por ser propiedad de una entidad pública, de un empresario individual o de una empresa lucrativa; una cofradía de pescadores que no desarrolle ninguna actividad económica en favor de sus miembros; una cooperativa registrada pero que no cumple ni fines ni principios propios de las cooperativas (cooperativas falsas); una mutualidad o una cooperativa de crédito donde la gestión ya no es democrática, etc. 
tener consecuencias, el legislador debe dar seguridad jurídica, no sólo a las empresas sino también a la sociedad civil y demás administraciones, que confían en que dicho reconocimiento responde al cumplimiento de unos requisitos que han sido verificados. Se hace necesario por ello adoptar criterios que permitan determinar qué entidades de la economía social deben poder tener acceso al catálogo (en su caso) o ser acreedoras del sello de entidad de la economía social, y qué entidades podrán ser beneficiarias de las medidas de promoción. En estos momentos y a la vista de la recién publicada Estrategia Española de la Economía social (2017-2020) parece que esa función se encomienda a la Dirección General del Trabajo Autónomo, de la Economía Social y de la Responsabilidad Social de las Empresas y se desarrollará mediante la Orden Ministerial que contenga los requisitos necesarios para obtener el sello que identificará a todas y cada una de las empresas y organizaciones que conforman el sector de la economía social (Medida n 19 de la Estrategia). Pero esta competencia no es discrecional porque habrá que respetar los límites que marca la Ley de Economía Social y en particular los artículos 5 y 6 que comentamos.

En efecto, como vimos anteriormente, las entidades mencionadas en el artículo 5.1 de la Ley son entidades de la economía social ope legis, en atención a la forma o calificación jurídica de esas entidades. Precisamente porque su marco jurídico predetermina la mayor parte de los requisitos: actividad, fines y principios estructurales, como puso de manifiesto el Informe previo realizado por el Grupo de expertos $^{60}$. Pero como también hemos visto, esta catalogación ope legis goza de presunción iuris tantum y por tanto, podría revocarse, limitarse o condicionarse el mantenimiento de un determinado tipo de entidad incluida en el catálogo, previo informe del Consejo para el Fomento de la Economía Social. Por ejemplo, podría determinarse la exclusión del catálogo o sello de determinadas entidades o categorías de entidades que no cumplen los principios de la economía social ${ }^{61}$.

La inclusión de nuevos tipos de entidades en el catálogo, por la vía del artículo 5.2 va a exigir que se acredite el cumplimiento de esos mismos requisitos ${ }^{62}$ :

60 Vid nota 43.

61 Por su carácter público (algunos centros especiales de empleo); por no desarrollar actividades económicas (algunas asociaciones o fundaciones); o no desarrollar actividades económicas en interés de sus miembros (algunas cofradías de pescadores); por falta de democracia en su gestión (algunas cooperativas de crédito y sociedades agrarias de transformación); por incumplir el principio de puertas abiertas (algunas cooperativas que dificultan el ingreso de nuevos socios), etc.

62 A este respecto, puede ser muy útil tener en cuenta criterios ya aplicados en el marco jurídico de las entidades calificadas ope legis como de economía social. Así por ejemplo, la primacía de las personas y del objeto social sobre el capital se puede observar en el criterio utilizado para atribuir los derechos tanto políticos como económicos. La prevalencia del interés de los miembros o del interés general sobre el interés de lucro, también se puede deducir a la vista del destino que se da a los resultados del ejercicio y al patrimonio social a la liquidación de la entidad: si el interés prevalente es el interés general, el patrimonio resultante a la disolución de la entidad debe destinarse a dichos fines; si prevalece el interés de los miembros, deben destinarse los resultados preferentemente a mejorar los servicios prestados a éstos (descuentos, retribuciones, etc.); el capital aportado no se remunera o sólo limitadamente, etc. La gestión democrática no supone exclusivamente igualdad de voto de los miembros, pero sí debe reconocerse el derecho de voz y voto a todos los miembros, deben establecerse límites a la acumulación de poder, a este respecto es frecuente limitar el número máximo de votos que un solo miembro o grupo de interés puede tener en una asamblea, o reconocer el derecho de todos los miembros a ser electores y elegibles, incluyendo en ello a otros colectivos no miembros, como trabajadores o voluntarios. La adhesión voluntaria y abierta exige poner de manifiesto el fácil acceso a la condición de miembro de la entidad, la inexistencia de condiciones estatutarias injustificadas que lo impidan, o informar periódicamente sobre los ingresos y bajas de miembros y las razones de éstas. 
actividades, fines y principios estructurales como los de primacía de la persona y el objeto social sobre el capital, adhesión voluntaria y abierta, control democrático por sus miembros, autonomía de gestión e independencia de los poderes públicos, o destino de los resultados al objeto social, a fines de interés general o en favor del desarrollo sostenible ${ }^{63}$. Los principios funcionales al tener que ver con el comportamiento tienen menor relevancia en este momento porque su cumplimiento en un momento determinado no garantiza que sea una práctica consolidada (por ejemplo: igual salario entre hombres y mujeres, conciliación de la vida familiar, contratación de trabajador en riesgo de exclusión, etc.).

En el informe para la elaboración de una ley de fomento de la economía social se proponía la incorporación de la "empresa social" entre las entidades de la economía social ${ }^{64}$; sin embargo la ausencia en esos momentos de una definición legal en España de lo que debía entenderse por tal concepto impidió que se recogiera finalmente en la ley tal referencia. La Estrategia Española de la Economía Social 2017-2020 recobra el interés por el tema, y se propone como Medida $n^{\circ} 14$ el estudio del concepto de empresa social en el marco español y el análisis de su posible relación con los conceptos de empresa social en el ámbito europeo $^{65}$; para ver las posibilidades de su encuadre en la Ley 5/2011 de Economía

63 Los objetivos de desarrollo sostenible constituyen un conjunto de medidas que según Naciones Unidas deben adoptarse universalmente para poner fin a la pobreza, proteger el planeta y garantizar que todas las personas gocen de paz y prosperidad. Todas esas medidas se estructuran en torno a 17 objetivos: 1) Fin de la pobreza; 2) Hambre cero; 3) Salud y bienestar; 4) Educación de calidad; 5) Igualdad de género; 6) Agua limpia y saneamiento, 7) Energía asequible y no contaminante; 8) Trabajo decente y crecimiento económico; 9) Industria, innovación e infraestructura; 10) Reducción de las desigualdades; 11) Ciudades y comunidades sostenibles; 12) Producción y consumo responsables; 13) Acción por el clima, 14) Vida submarina; 15) Vida de ecosistemas terrestres; 16) Paz, justicia e instituciones sólidas, y 17) Alianzas para lograr los objetivos (http://www.un.org/sustainabledevelopment/es/objetivos-de-desarrollo-sostenible/)

64 El artículo 4 de la Propuesta de Ley de Fomento de la Economía Social establecía: "A los efectos de la presente ley, se consideran entidades de la Economía Social, entre otras, ..., las empresas sociales y, con carácter general, todas las asociaciones y entidades cuya organización y funcionamiento respondan principalmente a los principios ..." (Monzón, Calvo, Chaves, Fajardo y Valdés dal Re, 2010, 171)

65 El concepto de empresa social tiene todavía diversa significación según los Estados miembros de la Unión Europea como se puso de manifiesto en el estudio de su marco jurídico llevado a cabo para la Comisión Europea en "A map of social enterprises and their eco-systems in Europe" (2015), y publicado más tarde por sus autores en: https://esela.eu/wp-content/uploads/2015/11/legal_mapping_publication_051015_web.pdf. Sin embargo las instituciones europeas han avanzado más en consensuar una definición de empresa social. El Consejo de la Unión Europea adoptó en su reunión de 7 de diciembre de 2015 unas Conclusiones sobre la promoción de la economía social como motor clave del desarrollo económico y social en Europa (SOC 711/EMPL 464) en las que describe las empresas de economía social e incluye bajo dicho concepto formas organizativas como las cooperativas, mutuas, fundaciones y asociaciones, "así como nuevas formas de empresas sociales", entendiendo por empresa social el concepto definido en el Reglamento (UE) $\mathrm{N}^{\circ}$ 1296/2013 del Parlamento Europeo y del Consejo, de 11 de diciembre de 2013 relativo a un Programa de la Unión Europea para el Empleo y la Innovación Social («EaSI») (DO L 347/238 de 20.12.2013). Este Reglamento en su artículo 2 define la empresa social como aquella que, independientemente de su forma jurídica, presenta las siguientes características: a) de conformidad con su escritura de constitución, sus estatutos o cualquier otro documento constitutivo de la empresa, tiene como objetivo primordial la consecución de impactos sociales mensurables y positivos en lugar de generar beneficios para sus propietarios, socios y accionistas, y que: i) ofrece servicios o bienes con un elevado rendimiento social, y/o ii) emplea un método de producción de bienes o servicios que, represente su objetivo social; b) utiliza sus beneficios, en primer lugar, para la consecución de su objetivo primordial, y ha implantado procedimientos y normas predefinidos que regulan cualquier reparto de beneficios a los accionistas y propietarios, con el fin de garantizar que dicho reparto no vaya en detrimento de su objetivo primordial; y c) está gestionada de forma empresarial, transparente y sujeta a rendición de cuentas, en especial, fomentando la participación de los empleados, los clientes o los interesados afectados por su actividad empresarial. 
Social. Por tanto, no sería descartable la inclusión próximamente de un nuevo tipo entre las entidades de la economía social: la empresa social. Y otras organizaciones cuya vinculación con la economía social sería de interés analizar son, las comunidades de usuarios del agua y comunidades de regantes, cuando se proponen la explotación económica de tales recursos para interés de sus usuarios o con fines de interés general, ya que en su funcionamiento seguramente cumplirán con los principios orientadores de la economía social ${ }^{66}$.

En cuanto a la cuestión de si la incorporación de un tipo de entidad en el catálogo, puede considerarse suficiente prueba del cumplimiento de los fines y principios que exige la ley para ser beneficiario de las políticas de promoción de la economía social ${ }^{67}$, consideramos que no es suficiente. La incorporación al catálogo se realiza porque las características jurídicas del tipo de entidad vienen a coincidir con los fines y principios estructurales de las entidades de la economía social, y ello es relevante a efectos estadísticos y de visibilidad; pero no creemos que sea motivo suficiente para beneficiarse en todo caso de medidas de fomento, por lo que habrá que estar a las concretas convocatorias de ayudas y cabrá esperar que la entidad tenga que demostrar en algún momento que su comportamiento se orienta conforme a todos los principios de la economía social, incluidos los principios funcionales y entre ellos los que son objetivos de la RSE.

En todo caso, debe tenerse en cuenta que: a) no puede discriminarse por razón de la forma jurídica ${ }^{68}, y$ b) debe evitarse la banalización de los rasgos propios de las entidades de la economía social, y como dice el Informe de la Subcomisión para el Fomento de la Economía Social deben establecerse barreras legales que impidan ser beneficiario de las políticas públicas de fomento de la economía social si no se cumplen las características específicas e propias de las entidades de la economía social (vid nota 21 pp. 7-8). De lo contrario se pondría en cuestión la utilidad de la propia ley de economía social.

Con anterioridad el Reglamento (UE) 346/2013, del Parlamento y del Consejo, de 17 de abril de 2013 sobre los fondos de emprendimiento social europeos (DOL 115, de 25.4.2013) define lo que denomina "empresas en cartera admisibles", concepto que Altzelai (2016) identifica con el de empresa social y propone como vinculante para los Estados. Sin embargo, dicho concepto no tiene más extensión que la que le reconoce el propio Reglamento y que limita al cumplimiento de sus propios efectos (art. 3).

66 Art. 81 del Texto Refundido de la Ley de Aguas, aprobado por Real Decreto Legislativo 1/2001, de 20 de julio.

67 El artículo 8 de la ley señala entre otras medidas de fomento: facilitar iniciativas económicas, facilitar el acceso a la innovación tecnológica y organizativa, involucrar a las entidades en políticas activas de empleo, fomentar el desarrollo de la economía social en áreas como el desarrollo rural, 1 dependencia o la integración social. Y más ampliamente la Subcomisión para el fomento de la economía social (ver nota 21), recomienda numerosas medidas de fomento, entre otras: facilitar el acceso a la financiación de las empresas de la economía social o crear premios y reconocimientos para las empresas más destacadas en el ámbito de la economía social (Recomendación $\mathrm{n}^{\circ} 30$ ).

${ }^{68}$ Actualmente, la ley de economía social acoge como entidades de la economía social a entidades que adoptan formas jurídicas muy variadas (asociación, sociedad civil, sociedad mercantil, fundación, cooperativa, mutualidad, incluso entidades sin personalidad jurídica), se responde con ello a la recomendación realizada por el CESE (vid nota 10 p. 53) de basar la calificación en los objetivos y actividades y no en las formas tradicionales de asociación, fundación, cooperativa y mutualidad). Así mismo, el Informe de la subcomisión destaca la importancia de adoptar el criterio de la no discriminación hacia las distintas formas de empresa (ver nota 21, p. 5). 
Por último, cabe preguntarse qué medios pueden utilizarse para justificar el cumplimiento de estos principios. La ley no dice nada al respecto y es de esperar que será la Orden Ministerial la que desvele esta incógnita. La subcomisión para el fomento de la economía social recomienda que las entidades de la economía social elaboren y difundan "memorias de sostenibilidad, preferentemente de acuerdo a estándares reconocidos internacionalmente, como el impulsado por la Global Reporting Initiative", y añade que, estas empresas "deben informarse sobre sus prácticas y sistemas de gestión a través de indicadores ambientales, económicos y sociales. Es necesario evitar informes poco rigurosos y con información dispersa, a través de los cuales los grupos de interés no puedan llevar a cabo un seguimiento del grado de cumplimiento por parte de las empresas de sus compromisos"69. También la Estrategia de la Economía Social insiste en ello, y dedica varias medidas a impulsar que las entidades de la economía social realicen memorias de RSE $\left(n^{\circ} 55\right)$ y le sean de aplicación herramientas de medición de la RSE existentes ( $\left.n^{\circ} 58\right)$.

Pero las entidades de la economía social (sus miembros, trabajadores y grupos de interés) deberían conocer también cuál es el grado de cumplimiento de los demás principios de la economía social. Ello no se alcanza sólo con la elaboración de la memoria de RSE, se hace preciso completar ésta con otros elementos de análisis que reflejen el grado de satisfacción en el cumplimiento de los principios.

En la práctica las empresas de economía social utilizan diversos instrumentos para reflejar, medir y comparar sus avances en el cumplimiento de sus principios, el más recomendado posiblemente sea el Balance Social ${ }^{70}$, pero también se realizan Memorias de sostenibilidad y Balances del Bien Común ${ }^{71}$.

Todos ellos son útiles y aceptables, pero la Memoria que se integra en las Cuentas Anuales, ofrece la ventaja de que es un documento contable, con valor jurídico y obligatorio para todo empresario. La Memoria debe aportar la información que sea necesaria para reflejar fielmente, no sólo el patrimonio y la situación financiera de la empresa, sino también los resultados conseguidos (art. 34 del Código de comercio), resultados que no tienen porqué ser exclusivamente financieros. Así por ejemplo las sociedades de capital deben dar cuenta en la Memoria del número medio de personas empleadas, los gastos de personal (sueldos, cargas sociales, pensiones, etc.); la distribución por sexos del personal de la sociedad (desglosado categorías y niveles, y entre éstos: altos directivos y consejeros); importe de los sueldos, dietas y remuneraciones de cualquier clase devengados por el personal de alta dirección y miembros del órgano de

69 Ver nota 21 p. $8-9$.

70 El Balance Social ha sido utilizado frecuentemente por las cooperativas para informar sobre el cumplimiento de sus principios (Mugarra 2001 y 2002). Posteriormente se ha extendido a las entidades de la economía social (Marcos de Castro 2003, y Mugarra, 2004) y de la llamada economía solidaria. Como dice la Red de Economía Solidaria de Cataluña (XES) en su web, el Balance Social, una herramienta de rendición de cuentas y medida de impacto social, ambiental y de buen gobierno. Las organizaciones que lo hacen pueden utilizar los resultados para mejorar internamente y a la vez, esta información permite tener datos agregados de los estándares éticos de la Economía Solidaria y del Mercado Social (http://xes.cat/es/comisiones/balancesocial/).

71 La Generalitat Valenciana promueve la realización del Balance del Bien Común y financia su elaboración no preceptiva (artículo 26 de la Orden 2/2017, de 1 de febrero, de la Consellería de Economía Sostenible, Sectores Productivos, Comercio y Trabajo, por la que se establecen las bases reguladoras para la concesión de ayudas destinadas a la promoción de la economía sostenible). 
administración, y obligaciones contraídas en materia de pensiones o pago de primas de seguros de vida (art. 260 Ley de Sociedades de Capital). Las cooperativas, también deben informar en su Memoria de las dotaciones y aplicaciones del Fondo de Educación, Formación y Promoción (Normas 13ª Orden EHA/3360/2010 sobre aspectos contables).

El Informe de gestión, también forma parte de los documentos contables, y debe contener (art. 19 Directiva 2013/34/UE sobre estados financieros anuales) información financiera y no financiera (sobre medio ambiente y personal de la empresa), pero esta información no financiera no es exigible a las pequeñas empresas $^{72}$. Por otra parte, la legislación cooperativa exige que este Informe recoja las variaciones habidas en el número de socios (art. 61.3 Ley de Cooperativas 27/1999), dato fundamental para conocer si se cumple el principio de libre adhesión y si la cooperativa satisface las necesidades de sus socios. El Informe de gestión también puede ser útil como vehículo de información sobre el cumplimiento de estos principios de las entidades de economía social, el problema es que no todas las empresas tienen que elaborar este Informe. Aquellas que pueden presentar un balance abreviado no tienen obligación de elaborarlo (art. 262.3 Ley de Sociedades de Capital).

La Memoria en cambio debe ser elaborada y aprobada por sus órganos sociales y en ocasiones auditada, y en todo caso finalmente, deberá ser depositada en un Registro público, por lo que reúne mejores condiciones para que las entidades de la economía social conozcan y difundan en qué grado cumplen con los fines y principios de la economía social. No es necesario que una ley imponga su elaboración para que las entidades de la economía social por responsabilidad y transparencia comiencen a integrar en sus Memorias del ejercicio información sobre el cumplimiento de los principios de la economía social.

\section{Conclusiones}

El análisis realizado de los preceptos de la Ley que regulan la identificación de las entidades de la economía social nos ha planteado diversas cuestiones que hemos ido analizando.

Como hemos visto, las entidades de la economía social se caracterizan por la concurrencia de una serie de requisitos:

a) Son personas jurídicas de derecho privado.

b) Son entidades que desarrollan actividades económicas con criterios empresariales, lo que permite también ser denominadas "empresas".

c) Con dichas actividades persiguen satisfacer una serie de necesidades o intereses, de sus miembros como usuarios de la actividad, y también intereses generales o de la comunidad.

d) Esas entidades actúan conforme con ciertos principios orientadores, que hacen prevalecer a las personas y el servicio que se les presta por encima

72 Están excluidas aquellas sociedades que en dos ejercicios consecutivos reúnan dos de estas condiciones: i) cuyo activo no supere los 11.400 .000 euros; ii) su cifra de negocios no supere los 22.800.000 euros, y iii) el número medio de trabajadores empleados durante el ejercicio no sea superior a 250 (art. 258 LSC). 
del capital; defienden y aplican la solidaridad y la responsabilidad; sus miembros controlan democráticamente la entidad; la admisión de miembros es voluntaria y abierta; su gestión es autónoma e independiente de los poderes públicos y destinan sus beneficios a mejorar el servicio que prestan a sus miembros, a fines de interés general o a objetivos de desarrollo sostenible.

Estos requisitos están recogidos en la Ley española de economía social, aunque de forma incompleta y menos precisa. Por ello, hemos propuesto que se haga una interpretación de los fines y principios de la economía social que sea conforme con las recomendaciones realizadas por las instituciones europeas.

Por otra parte, el tenor de la ley da a entender que determinas entidades, por su forma o calificación jurídica son, ope legis, entidades de economía social, mientras que las demás entidades tendrán que demostrar que cumplen los requisitos para obtener esa calificación. Las entidades seleccionadas en la ley como entidades de la economía social lo han sido porque previamente se ha comprobado que cumplen mayoritariamente con los fines y principios de la economía social, o al menos, con los principios estructurales. Las entidades que accedan al catálogo por la vía del artículo 5.2 tendrán que demostrar igualmente el cumplimiento de los mismos requisitos.

Las particulares entidades de la economía social no necesitan actualmente inscribirse en un registro para recibir esta calificación y no se someten por tanto a un control sobre si cumplen todos los requisitos o no, pero, y hasta que se regulen las condiciones que acrediten la obtención del Sello de Entidad de la Economía Social, deberían analizar voluntariamente en qué medida cumplen los principios de la economía social (entre los que se encuentran los objetivos de la RSE), y orientar su actividad hacia un mayor cumplimiento de los mismos. Por ello es recomendable la elaboración de un balance social o memoria de sostenibilidad que dé cuenta a los miembros, trabajadores y grupos de interés, del cumplimiento de esos principios, o integren esa información en la Memoria anual que todo empresario debe elaborar, aprobar y publicar.

Las administraciones públicas, en el cumplimiento de sus políticas de promoción de la economía social deberían tener en cuenta también y asegurarse, de que las entidades beneficiarias de esas políticas, cumplen con los fines y principios que caracterizan a las entidades de la economía social. Un control en la aplicación de estas políticas contribuirá sustancialmente a legitimar esas políticas y a impulsar el desarrollo de la economía social.

\section{Referencias bibliográfícas}

Alfonso Sánchez, R. (2010) Algunas consideraciones en torno a la Propuesta de Ley "Marco" de Economía Social. REVESCO. Revista de Estudios Cooperativos, Segundo Cuatrimestre, $\mathrm{N}^{\circ} 102$, pp. 7-23.

Altzelai Uliondo, I. (2016) Otro enfoque para las entidades de la Economía Social, CIRIEC-España. Revista Jurídica, № 28. 
Arana Landín, G. (2010) La Economía Social en la vanguardia de la Responsabilidad Social de la empresa. Revista vasca de economía social = Gizarte ekonomiaren euskal aldizkaria, № 6, pp. 71-91.

Arana Landín, S. (2012) Sobre el nuevo concepto de economía social en la Ley 5/2011, de 29 de marzo, de economía social en España y sus posibles consecuencias tributarias. Revista vasca de economía social, $\mathrm{N}^{\circ} 8$, pp. 85-110.

Arrieta Idiakez, F.J. (2014) Concreción de las entidades de la economía social. REVESCO. Revista de Estudios Cooperativos, Tercer Cuatrimestre, $\mathrm{N}^{\circ} 116$, pp. 36-56. DOI: 10.5209/rev_REVE.2014.v116.45717.

Barea Tejeiro, J. y Monzón Campos, J.L. (Dir.) (1995), Las cuentas satélite de la economía social en España: Primera aproximación, Valencia, CIRIEC-España.

Borjabad Bellido, J.V. (2013) La libre adhesión y baja voluntaria del socio en la legislación cooperativa catalana y sus consecuencias económicas. Tesis Doctoral, Universitat de Lleida.

Calvo Ortega (2005) Entidades de Economía Social: razones de una fiscalidad específica, en Fiscalidad de las Entidades de Economía Social. (Coord.: Rafael Calvo). ThomsonCivitas, Cizur Menor, Navarra, pp. 33-63.

Cervera Paz, A. (2010) Percepción cooperativa de las cofradías de pescadores: un estudio empírico. REVESCO. Revista de Estudios Cooperativos, Tercer Cuatrimestre, № 103 , pp. 7-32.

Chaves, R. y Monzón, J.L. (2008) La Economía Social en la Unión Europea. Comisión Económica y Social Europea.

De Castro Sanz, M. (2003) Responsabilidad social de las empresas y la economía social. Responsabilidad social de las empresas y balance social. Coord. por Francisco Salinas Ramos, Ed. Universidad Católica de Ávila, pp. 159-164.

Domínguez Cabrera, M. del P. (2011) La cooperativa como elemento subjetivo de la responsabilidad social corporativa. Revista de derecho mercantil, $\mathrm{N}^{\circ} 282$, pp. 187-208.

Duque Domínguez, J.F. (1986) La libre adhesión y el principio de puertas abiertas en las sociedades cooperativas, en AAVV Primeros encuentros cooperativos de la UPV, Bilbao, pp. 183-222.

Etxezarreta, E. y Morandeira, J. (2012) Consideraciones conceptuales sobre la Economía Social a la luz de la Ley 5/2011. Revista vasca de economía social = Gizarte ekonomiaren euskal aldizkaria, №. 8, pp. 7-36.

Fajardo García, G. (1997) La gestión económica de la cooperativa: responsabilidad de los socios. Tecnos, Madrid.

Fajardo García, G. (2010) Escenarios jurídicos de la economía social y de los agentes que la integran en la Unión Europea y en los países miembros. Noticias de la economía pública social y cooperativa, $\mathrm{N}^{\circ} .54, \mathrm{pp} .42-52$.

Fajardo García, G. (2012) Las empresas de economía social en la Ley 5/2011, de 29 de marzo, $R d S$, No 38 , pp. 245-280.

Feliú Rey, M.I. (2011) Claroscuros de la Ley 5/2011 de Economía Social. Anuario de Derecho de Fundaciones, N. 1, pp. 117-152.

Gadea Soler, E. (2012) Delimitación del concepto de cooperativa: de los principios cooperativos a la responsabilidad social corporativa. CIRIEC-España. Revista Jurídica de Economía Social y Cooperativa, № 23, pp. 37-58.

Martínez Charterina, A. (2014) Cooperativas y responsabilidad social empresarial. Deusto Estudios Cooperativos, $\mathrm{N}^{\circ}$. 4, pp. 49-62

Martínez Charterina, A. (2017) El principio de adhesión voluntaria y abierta desde una perspectiva histórica y doctrinal. Boletín de la Asociación Internacional de Derecho 
Cooperativo, $\mathrm{N}^{\mathrm{o}}$ 51, (ejemplar dedicado a: la adhesión voluntaria y abierta), pp. 179190.

Montesinos, S. (2012) Ley de Economía Social, interés general y regímenes tributarios especiales. CIRIEC-España. Revista Jurídica de Economía Social y Cooperativa, № 23 , pp. 9-35.

Monzón, J.L; Calvo Ortega, R; Chaves, R; Fajardo, G. y Valdés Dal Re, F. (2010) Informe para la elaboración de una Ley de Fomento de la Economía Social. Ministerio de Trabajo e Inmigración, Madrid.

Monzon, J.L y Chaves, R. (2012) La Economia Social en la Union Europea. Comite Económico y Social Europeo, Bruselas.

Morgado Panadero, P. (Coord,) (2012) La ética en el sistema de producción: economía social y responsabilidad social empresarial. Thomson Reuters-Civitas, Cizur Menor, Navarra.

Mozas Moral, A. y Puentes Poyatos, R. (2010) La responsabilidad social corporativa y su paralelismo con las sociedades cooperativas. REVESCO. Revista de Estudios Cooperativos, Tercer Cuatrimestre, № 103, pp. 75-100.

Mugarra Elorriaga, A. (2001) Responsabilidad y Balance Social hoy en día: un reto para las Cooperativas. CIRIEC-España. Revista de Economía Pública, Social y Cooperativa, № 39, (Ejemplar dedicado a: Balance social en la economía social), pp. 25-50.

Mugarra Elorriaga, A. (2002) Responsabilidad y balance social: un reto para las cooperativas. Noticias de la economía pública social y cooperativa, $\mathrm{N}^{\circ}$. 35, pp. 30-34.

Mugarra Elorriaga, A. (2004) Balance social y responsabilidad social en las empresas de economía social. Mediterráneo económico, $\mathrm{N}^{\circ}$. 6, (Ejemplar dedicado a: Economía social: la actividad económica al servicio de las personas / coord. por Juan Francisco Juliá Igual), pp. 311-331.

Namorado, R (2017) O que é a economía social?, En Economía Social em Textos, Centro de Estudos Cooperativos e da Economía Social, $\mathrm{N}^{\mathrm{o}}$ 1, Janeiro 2017 (http://www.uc.pt/feuc/ceces/est/1).

Padilla Ruiz, P. (2011) Comentarios a la Ley 5/2011, de Economía Social, Revista Aranzadi Doctrinal 3, pp. 129-137

Paniagua, M (2011) Las empresas de la economía social. Más allá del comentario a la Ley 5/2011, de economía social. Marcial Pons, Madrid, Barcelona, Buenos Aires.

Paz Canalejo, N. (2012) Comentario sistemático a la Ley 5/2011, de Economía Social. Tirant lo Blanch,Valencia.

Pedrosa Ortega, C. y García Martí, E. (2011) El gobierno en la sociedad cooperativa como base de la cohesión social: el caso de una sociedad cooperativa agraria. REVESCO. Revista de Estudios Cooperativos, Tercer Cuatrimestre, № 106, pp. 7-32. DOI: 10.5209/rev_REVE.2011.v106.37372.

Sánchez Pachón, L.A. (2010) El reconocimiento de la economía social y de sus agentes en el proyecto de Ley de Economía Social. Noticias del CIDEC, № 54/2010.

Serrano Soldevilla, A.D. (1982) La cooperativa como sociedad abierta. Madrid.

Socias Salvá, A. y Horrach Roselló, P. (2013) Enfoque de la responsabilidad social y la transparencia en empresas de economía solidaria. CIRIEC-España. Revista de Economía Pública, Social y Cooperativa, No 77 (Ejemplar dedicado a: Responsabilidad social empresarial, finanzas y capital social en la economía social), pp. 31-58.

Vargas Vasserot, C. (2006) La actividad cooperativizada y las relaciones de la cooperativa con sus socios y con terceros. Pamplona; Thomson-Aranzadi. 
Vargas Vasserot, C. (2015) El principio cooperativo de puertas abiertas (adhesión voluntaria y abierta). Tópico o realidad en la legislación y en el práctica societaria. CIRIEC-España. Revista Jurídica, № 27, pp. 133-173.

Vázquez Pena, M.J. (2016-2017) La Ley de la economía social de Galicia: especial referencia a la modificación de la ley gallega de cooperativas. Cooperativismo $e$ economía social, $\mathrm{N}^{\circ} 39$, pp. 433-441. 